\title{
How we did it: the development of a specialist registrar training programme by the Mersey Accident and Emergency Trainees' Association
}

\author{
F Davies, U Geary, T Soulsby, A Good
}

\begin{abstract}
Over the last three years the accident and emergency trainees in Merseyside have developed a self directed training programme which now consists of twice monthly meetings. This has been achieved through a process of evolution, shaped by the core curriculum, and supervised by the region's consultants with the support of the postgraduate dean. The meetings have proved both popular and valuable. The development and format of the scheme is presented in the hope of stimulating others to work together to improve the training of specialist registrars. (f Accid Emerg Med 1997;14:321-323)
\end{abstract}

Keywords: training; accident and emergency; specialist registrar; education

Many recent changes have occurred in postgraduate medical education with the advent of the Calman reforms and the specialist registrar $(\mathrm{SpR})$ grade which was designed to "produce a shorter, more structured and organised training so that independent clinical competence can be achieved much earlier than in the past in many disciplines". ${ }^{1}$ In accident and emergency (A\&E) we have also seen the formation of the Faculty of Accident and Emergency Medicine and the introduction of the Fellowship examination.

Traditionally the transfer of knowledge and

Accident and

Emergency

Department, Royal

Liverpool University

Hospital, Liverpool

F Davies

U Geary

T Soulsby

A Good

Correspondence to:

Dr Tom Soulsby, Senior Registrar, Accident and Emergency Department, Fazakerley Hospital,

Longmoor Lane, Liverpool L9 7AL, UK.

Accepted for publication 12 February 1997 skills in postgraduate medicine has been based system and private study. Where formal teaching occurred it was often didactic or captious. In recent years we have seen the development of trust based half day educational and audit programmes, continuing medical education for career grade doctors, and induction programmes or examination based courses for senior house officers. However, in many specialties the training grades have little in the way of a structured learning programme. Specialist registrars need a teaching programme specifically directed at their needs. The need for such a programme is greatest in $A \& E$, where there is a unique diversity of clinical predominantly through an apprenticeship problems, inevitable difficulties in staying abreast of recent developments in all fields, and limited time for direct consultant supervision compared with other specialties.

The Calman implementation steering group also stated that "the successful introduction of the new training programmes will require a flexible partnership between all those involved". ${ }^{1}$ As trainees in the Mersey subregion, we would like to describe how we developed our own specialist registrar programme, with the support of our consultants.

\section{Aims of the programme}

The programme is designed to complement the training received in trainees' own departments, to encompass all the skills required to be a consultant, and to be conducted in a stimulating and non-threatening manner. We aim to cover the following areas of training:

- Knowledge of the core curriculum set by the Faculty of Emergency Medicine. The whole syllabus will be covered over a two to three year period;

- Preparation for the FFAEM examination;

- Acquisition of practical skills relevant to clinical practice;

- Acquisition of non-clinical skills, for example management of departments and personnel, communication, budgeting, audit, and computer skills;

- Learning to perform research of acceptable scientific quality;

- Keeping abreast of important changes in practice;

- Facilitating access to information not easily gained from books, courses, or conferences. As well as increasing our knowledge and skills in the topics listed above, the meetings are also of value in providing a useful forum for communication and collective discussion of all issues related to $A \& E$ training. Examples of this have included topics such as the reorganisation of the specialist registrar rotations, how to organise an elective period abroad, and an invitation to the regional adviser to update us on issues relating to the Certificate of Completion of Specialist Training and the specialist registrar grade. 
Table 1 Essential requirements in establishing a specialist registrar training programme

"Protected time" for meetings, that is, inclusion within contracted hours and organisation of departmental staffing levels to allow attendance

Support of the Regional postgraduate dean and the local specialist education and training committee

An appropriate curriculum, sensitive to needs of trainees

Meetings not exceeding a critical size ( 15 persons)

A balance of teaching methods

A reservoir of enthusiastic, effective teachers

Regular appraisal of each component

\section{Organisation}

In organising the programme we wished to adopt a flexible approach and to adapt to constructive criticism or suggestions. The development of the content of the programme over two years was therefore an evolutionary process which took the opinions of the trainees into account at each stage. This process illustrates many of the recognised principles of effective adult training programmes in that it is based upon our own awareness of our training need (internal motivation), it provides solutions to the problems we encounter in our clinical work (personal responsibility), it is integrated into our professional work, and through it we are the architects of our own education. ${ }^{2}$

We sought the guidance and support of the postgraduate dean and the specialty training and education committee (STEC), formerly the postgraduate advisory panel. Our proposals were enthusiastically received and two consultants volunteered to act as educational supervisors to the programme.

Evaluation forms are completed by each trainee every six months and this assists us in reporting back to the supervising consultants and the STEC, and in planning future meetings and speakers. This continuous appraisal is crucial to the maintenance of a high quality training programme, sensitive to trainees' needs.

The finer details of organisation of such a training programme are inevitably dependent on a region's geography and teaching resources. However, some principles are fundamental in setting up a specialist registrar training programme (table 1). Of critical importance is the principle that training time is protected through inclusion within contracted hours and organisation of individual $A \& E$ departments' staffing levels to allow their trainees to attend meetings. An attendance register is kept.

Our meetings evolved from an informal evening once monthly, through an afternoon meeting with guest lectures, to a complex programme which is intended to "roll" over a two to three year period. Meetings are held twice monthly from $2.00-5.30 \mathrm{pm}$ and are divided notionally into the first, " $A$ " meeting and the second, " $B$ " meeting, which have different formats (table 2). The venue for the meetings rotates around the region's eight hospitals. Standard expenses for speakers from outside the region are funded through the deanery's office for postgraduate education and training.

Three of the trainees act as joint coordinators since there is a considerable demand on
Table 2 Format of meetings

" $A$ "Meetings
Guest lecture $(50 \mathrm{~min})$
Guest lecture $(50 \mathrm{~min})$
Coffee/update time $(30 \mathrm{~min})$
Guest lecture $(50 \mathrm{~min})$
Special topic $(30 \mathrm{~min}):$ trainee presentation
Special topic example: carbon monoxide poisoning,
anaphylaxis, methanol poisoning
" $B$ "Meetings
One or more of:
Research workshop
Statistics workshop
Practical skills workshop
Management topic
Journal club
Management topic examples: budgeting, ordering equipment,
interviewing, major incident policy design

each person's time to organise the programme. The three meet regularly to plan the framework of each meeting so that speakers can be contacted well in advance. The trainee at each hospital is responsible for the detailed organisation of the meetings. The three coordinators act as central contact points and provide representation to the STEC and to the British A\&E Trainees' Association.

In the selection of speakers we are careful to approach those who we feel understand $A \& E$ trainees' requirements for knowledge, are enthusiastic, and who will adopt an informal approach to the lecture, allowing adequate time for dialogue. Limitation of the size of the meetings is therefore important, so although $\mathrm{A} \& \mathrm{E}$ consultants contribute regularly to the meetings, they are not normally in attendance. As well as relying upon traditional lectures to cover many topics, we encourage the use of other educational techniques such as small group work, problem based sessions, quizzes, and practical workshops when appropriate. Guest speakers are asked to provide handouts whenever possible.

Research has been given a high profile in the programme. The emphasis is on open discussion of research projects with the aim of improving the quality of the work. We have invited input from statisticians and consultants who have an interest in research. Research methodology, statistical analysis, and computer technology are covered. We plan to coordinate individual research projects, thus reducing the recognised problems associated with moving from hospital to hospital. We also intend to establish multicentre trials for the less common subjects. We hope that as a result we will see improvements in the quality of research around the region and coordination of projects with greater input from consultants and statisticians. We keep a database of feedback forms which we complete after attending courses, conferences, and scientific meetings so that other trainees have more information when deciding whether to attend future meetings.

The evaluation forms have shown that not only is the programme proving successful in achieving our educational goals, but that trainees find it invaluable in fostering a mutually supportive atmosphere, where they can develop a closer working relationship with each other. This unity as a group will hopefully 
strengthen with the advent of five year training periods.

\section{Summary}

The Mersey A\&E trainees have developed a successful self directed rolling programme of education which is extensive and concentrated. The programme covers both clinical and nonclinical aspects of training, namely management and research skills. The twice monthly meetings now form an integral and compulsory part of the specialist registrar training. Meetings are popular and well attended and afford greater cohesion as a region. We hope that the programme described will train us in all the aspects needed to make us better consultants in the future.

We would like to thank the following people for their support in establishing the programme: $\mathrm{Dr} J$ Bache, Mersey regional advisor in A\&E; Dr Trevor Bailey, regional postgraduate dean; Dr L Jaffey and Dr S Graham, consultants in A\&E medicine and programme supervisors; and the other trainees, past and present, but currently including Peter Ahee, Evan Bayton, Graeme Inkster, Alan Pinto, Ann Robertson, David Roe, Alison Smith, and Elspeth Worthington.

1 Department of Health. A guide to the specialist registrar training. London: Department of Health, 1996 (3753 1P 48K Mar 96 (03)).

2 Knowles $M$. The adult learner: a neglected species. Houston: Gulf Publishing Company, 1990.

\section{BAEM 98 Birmingham}

\section{April to 1 May 1998}

DEBATES: How much care in A\&E?

Doctors, nurses or paramedics in $A \& E$ ?

FREE PAPERS

WORKSHOPS: Statistics

CLINICAL GRAND ROUNDS

Writing papers

Law of consent

Negligence

Qualitative research

Invasive monitoring

EDUCATION IN A\&E

RTA EXTRICATION DEMONSTRATION

\section{At: International Convention Centre}

within walking distance of National Sea Life Centre,

Ronnie Scotts, Symphony Hall, and the National Indoor Arena

Details from: BAEM 98, c/o A\&E, City Hospital, Dudley Road, Birmingham B18 7QH 